\title{
SISTEM MONITORING PENCEMARAN POLUTAN KENDARAAN VIA GADGET BERBASIS ARDUINO
}

\author{
Adibatul Ardianto ${ }^{1)}$, Uswatun Khasanah ${ }^{2)}$, Brian Dwi Murdianto ${ }^{3)}$, Bekti Wulandari ${ }^{4)}$ \\ ${ }^{122) 344)}$ Pendidikan Teknik Elektronika, Teknik, Universitas Negeri Yogyakarta \\ Email: adibatulardianto1987@gmail.com
}

\begin{abstract}
Sources of air pollution one of them is motor vehicle exhaust gas, the gas produced from the combustion of fuel occurs at vehicle engine. Application detection level of the exhaust system of motor vehicles that are made used to detect the amount of gas levels of $\mathrm{H}_{2}, \mathrm{EtOH}$ and $\mathrm{CO}$ gases using the sensor TGS2201. Data from sensors is processed by the arduino and the results are displayed on the application android through Bluetooth HC05, the design of an application program using the C programming language.
\end{abstract}

Keywords: gas,arduino, sensors,TGS2201, and Bluetooth HC05

\begin{abstract}
ABSTRAK
Sumber polusi udara salah satunya adalah gas buang kendaraan bermotor, gas yang dihasilkan dari pembakaran bahan bakar terjadi pada mesin kendaraan. Tingkat deteksi aplikasi dari sistem pembuangan kendaraan bermotor yang dibuat digunakan untuk mendeteksi jumlah kadar gas $\mathrm{H}_{2}$, gas EtOH dan gas $\mathrm{CO}$ dengan menggunakan sensor TGS2201. Data dari sensor diolah oleh arduino dan hasilnya ditampilkan pada PC melalui port serial, desain program aplikasi dengan menggunakan Bahasa $\mathrm{C}$.
\end{abstract}

Kata kunci: gas, arduino, sensor,TGS2201, dan Bluetooth HC05

\section{PENDAHULUAN}

Pencemaran udara, masih menjadi ancaman bagi warga. Beberapa kalangan memastikan, pencemaran itu banyak dihasilkan dari kendaraan pribadi. Namun ironisnya, pemerintah hingga kini belum melakukan penegakkan hukum bagi kendaraan yang tidak lolos uji emisi. Komisi Penghapusan Bensin Bertimbal (KPBB) memastikan, terjadi lonjakkan cukup drastis tingkat pencemaran udara Jakarta pada 2011 dibandingkan 2010.

Proses uji emisi kendaraan yang dilakukan oleh kementrian perhubungan dan kepolisian pada setiap kendaraan milik pribadi maupun angkutan umum, dinilai oleh beberapa kalangan masih setengah hati. Kementrian Lingkungan Hidup, mendesak Kepolisian dan Kementrian Perhubungan agar menindak tegas pemilik kendaraan yang tidak lolos uji emisi. Asisten Deputi Pengendalian Pencemaran Kementrian Lingkungan Hidup Ade Palguna menegaskan, kendaraan pribadi memiliki andil yang cukup besar dalam pencemaran di Ibukota dibandingkan dengan angkutan umum.

Transportasi merupakan salah satu sarana pendukung yang dibutuhkan untuk aktifitas dan kegiatan manusia. Kebutuhan sarana transportasi bagi masyarakat saat ini semakin meningkat, hal tersebut berdampak pada meningkatnya pencemaran udara yang dihasilkan dari gas buang kendaraan bermotor. Kendaraan bermotor mengeluarkan berbagai jenis gas maupun partikulat yang terdiri dari berbagai senyawa anorganik dan organik serta zatzat berbahaya lainnya yang berasal dari hasil pembakaran bahan bakar pada mesin 
kendaraan yang dapat menimbulkan dampak negatif, baik terhadap kesehatan manusia maupun terhadap lingkungan, diantaranya adalah Karbon Monoksida $(\mathrm{CO})$, gas Hidrogen $\left(\mathrm{H}_{2}\right)$, dan unsur gas lainnya termasuk partikulat debu. Penelitian ini dimaksudkan membuat suatu alat pengukuran konsentrasi gas yang dideteksi oleh sensor TGS 2201 untuk mengetahui tingakat emisi gas buang kendaraan bermotor dengan menampilkan jumlah kadar gas Karbon Monoksida (CO), gas Hidrogen $\left(\mathrm{H}_{2}\right)$, dan gas Etanol (EtOH) dalam satuan PPM yang akan ditampilkan dalam aplikasi android.

\section{Sensor Gas TGS 2201}

Sensor adalah jenis tranduser yang digunakan untuk mengubah variasi mekanis magnetis, panas, sinar dan kimia menjadi tegangan dan arus listrik. Sensor TGS 2201 memiliki 2 elemen sensor yang dapat mendeteksi target gas Diesel dan Gasoline. Elemen Sensor ini terdiri dari lapisan logam oksida semikonduktor terbentuk pada substrat alumina yang dikemas dalam sebuah chip yang dapat mendeteksi keberadaan suatu gas, selain itu sensor TGS 2201 juga mempunyai sebuah pemanas (heater) yang digunakan untuk membersihkan ruangan sensor dari kontaminasi udara luar, agar sensor dapat bekerja kembali secara efektif. Perubahan konduktivitas pada sensor dipengaruhi oleh unsur gas tertentu sesuai dengan karakteristik gas yang dapat dideteksi oleh sensor tersebut. Karakteristik Elemen 1 pada sensor TGS 2201 berfungsi mendeteksi Gas buang Diesel (solar), sedangkan Elemen 2 pada sensor TGS 2201 berfungsi mendeteksi Gas buang Gasolin (bensin). Sumbu Y pada gambar berikut diindikasikan sebagai rasio Sensor Resistensi (Rs / Ro) yang didefinisikan sebagai berikut:

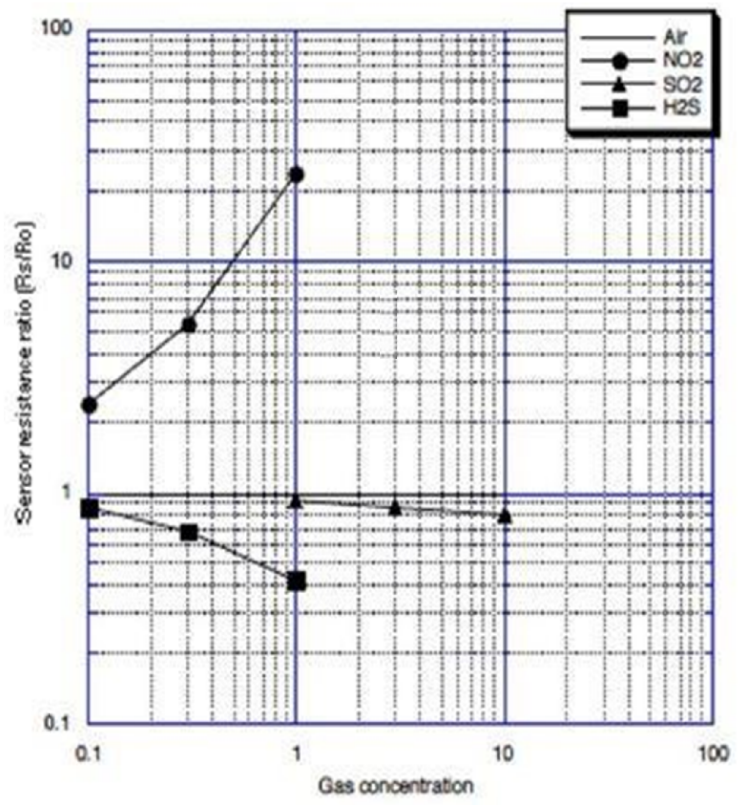

(a)

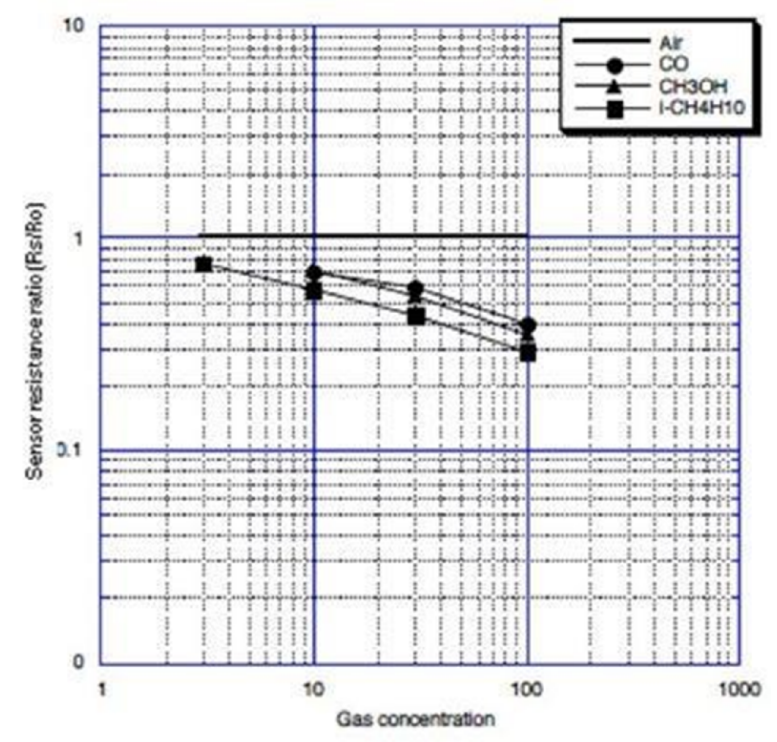

(b)

Gambar 1. (a). Karakteristik TGS 2201 Elemen 1 (b). Karakteristik TGS 2201 Elemen 2 Rs : Resistansi sen sor pada beberapa jenis gas Ro : Resistansi sensor pada udara bersih 
METODE PENELITIAN

\section{Perancangan Hardware}

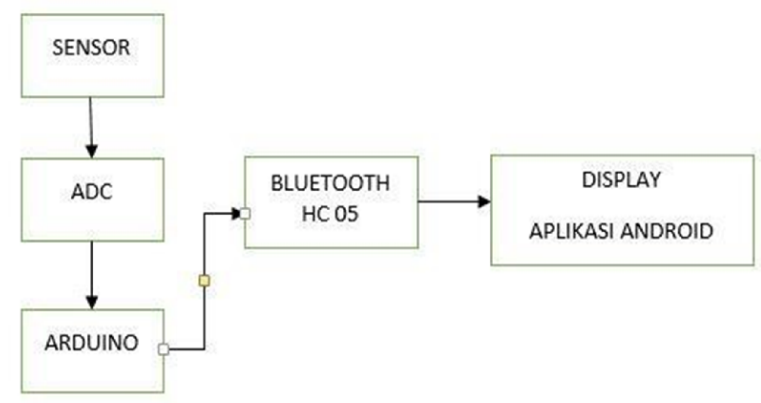

Gambar 2. blok diagram system

Sensor sebagai pendeteksi emisi gas buang kendaraan bermotor, sensor akan mengubah besaran kadar gas yang diterimanya menjadi besaran listrik, sinyal yang dikeluarkan oleh sensor akan dikirim ke ADC (Analog to Digital Converter) yang berfungsi sebagai pengubah data analog ke data digital yang selanjutnya diolah oleh Arduino. Data hasil dari Arduino akan dikirim ke Bluetooth HC05 sebagai media pengiriman data dari android ke hardware sistem monitoring pencemaran gas polutan kendaraan bermotor dan hasilnya ditampilkan pada aplikasi android.

\section{Perancangan Sensor Tgs 2201}

Output tegangan pada hambatan RL (Vout) digunakan sebagai masukan pada mikroprosesor. Nilai resistansi RL dipilih agar konsumsi daya dari sensor (Ps) di bawah batas $15 \mathrm{~mW}$, nilai Ps akan meningkat pada waktu nilai resistansi sensor $\mathrm{R}$ Ps sama dengan resistansi RL. Untuk mengetahui nilai resistansi sensor (Rs), dapat dihitung dengan menggunakan rumus:

$$
R s=\frac{V_{C}-V_{R L}}{V_{R L}} \times R_{L}
$$

Keterangan :

Vc : Circuit Voltage
VRL : Load Resistance Circuit Condition

RL : Load Resistance

Rs : Sensor Resistance

Hasil perubahan tersebut akan memberikan nilai tegangan yang berbedabeda sebagai sinyal output yang dihasilkan oleh sensor untuk menentukan unsur suatu gas yang terdeteksi. Sinyal output yang berupa nilai tegangan tersebut yang akan dikonversi melalui rangkaian ADC (Analog to Digital Converter) untuk menghasilkan data sinyal digital yang dapat diolah pada processor.

\section{Perancangan Sistem}

Pada perancangan sistem menggunakan Arduino sebagai pusat pemrosesan data.

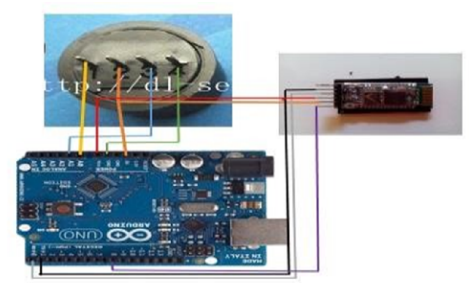

Gambar 3. Perancangan hardware

\section{Perancangan Software}

Perancangan perangkat lunak program utama ini secara garis besar bertujuan untuk mengatur kerja sistem seperti inisialisasi register I/O dan variabel, pembacaan hasil sensor, proses pengaturan sinyal kontrol. Program utama berperan sebagai jantung perangkat lunak yang akan mengatur keseluruhan operasi yang melibatkan fungsi-fungsi pendukung. Fungsi-fungsi pendukung akan melakukan kerja khusus sesuai kebutuhan dari program utama. Diagram alir program utama dapat dilihat pada Gambar 4. diagram alir pada software. 


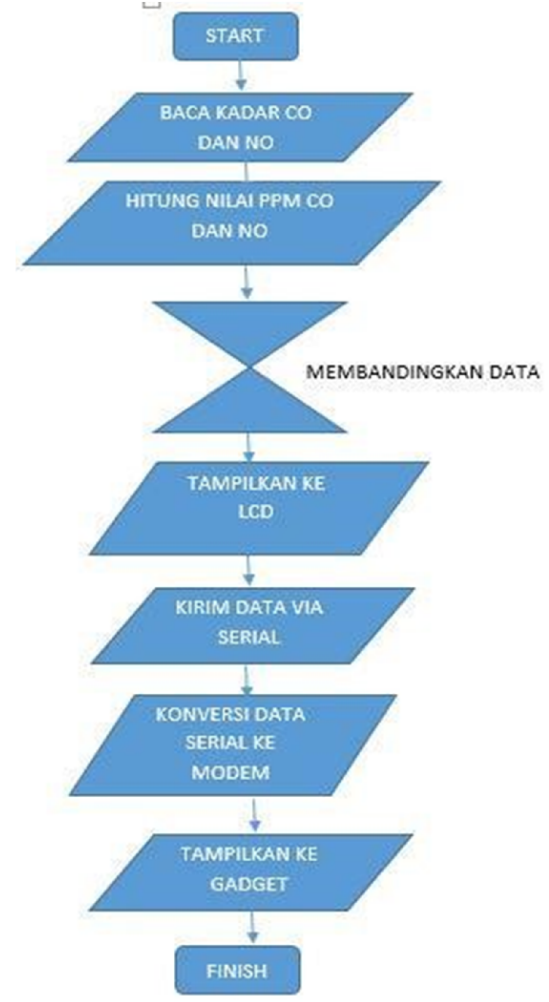

Gambar 4. Diagram alir rancangan

Prinsip kerja secara umum dari alat ini adalah, polutan yang mengandung gas $\mathrm{CO}$ dan NOx berlebih yang tertangkap, diidentifikasi berupa sinyal analog oleh sensor gas $\mathrm{CO}$ dan NOx. Kemudian sinyal analog tersebut diolah dan dibandingkan dengan data yang diperoleh sebelumnya oleh Arduino, oleh Arduino data analog diolah dan dikonversikan melalui ADC menjadi data digital dan kemudian data tersebut ditampilkan oleh LCD berupa persentasi nilai dalam satuan ppm dan di kirim melalui Komunikasi data melalui bluetooth HC 05 untuk ditampilkan di gadget.

\section{HASIL DAN PEMBAHASAN}

\section{Pengujian Sistem}

Pengujian sistem dibagi menjadi beberapa tahap, pertama pengujian perangkat keras dan pengujian perangkat lunak aplikasi sistem. Pengujian perangkat keras yang dilakukan adalah menguji sensor TGS 2201 dengan memberikan inputan berupa gas Nitrogen Oksida (NOx) dan Karbon Monoksida (CO) yang berasal dari asap kendaraan bermotor yang berbahan bakar bensin. Langkah pengujian emisi kendaraan dilakukan dengan cara menghidupkan sensor terlebih dahulu kurang lebih selama 3 menit, hal ini dibutuhkan sensor sebagai cleaning sensing pada elemen sensor dan juga sebagai kalibrasi sensor untuk nilai pada udara bersih. Langkah selanjutnya menempatkan sensor pada gas buang kendaraan kurang lebih 1 sampai 2 menit pada kondisi kendaraan idle dengan terlebih dahulu mematikan semua kelistrikan seperti AC, Radio/Tape, dan Lampu, lalu sensor akan mengukur kadar gas buang pada kendaraan yang diuji.

\section{Analisis Perangkat Keras}

Elemen sensor TGS 2201 terdiri dar lapisan - lapisan logam semikonduktor oksida yang terbuat dari kepingan elemen substrat oksid alumina bersama dengan heater yang diintegrasikan. Didalam elemen sensor dapat mendeteksi adanya gas, sensor dapat merubah konduktivitas gas bergantung pada konsentrasi gas tersebut di udara. Sensor ini mempunyai nilai resistansi Rs yang akan berubah bila terkena gas dan juga mempunyai sebuah pemanas (heater) yang digunakan untuk membersihkan ruangan sensor dari kontaminasi udara luar. Pemanas pada sensor memerlukan tegangan yang konstan yaitu lebih kurang 6 volt DC supaya sinyal output sensor selalu dalam keadaan stabil. Setelah kondisi nilai pada sensor stabil, sensor diletakkan pada belakang klanpot 
kendaraan, dalam proses ini data yang dicatat adalah perubahan tegangan keluaran sensor, volume kadar gas NO dan CO dalam satuan bentuk PPM (Part per Millions) dan prosentase jumlah. Arduino akan mengambil data tersebut untuk kemudian dikirimkan ke Android melalui Bluetooth HC 05.

\section{Hasil Program Aplikasi Sistem}

Pengujian software dilakukan untuk mengetahui apakah program dapat bekerja sesuai dengan konsep perancangan alat.

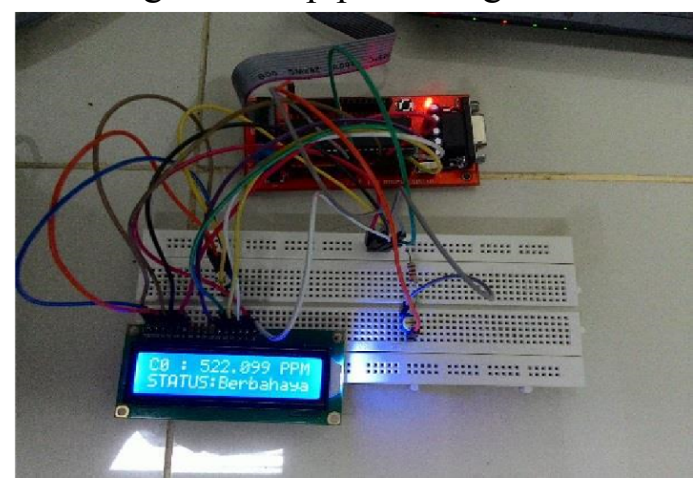

Gambar 5. hasil pengujian hardware sistem monitoring

Hasil aplikasi program sistem pendeteksi kadar gas buang kendaraan bermotor, pada gambar berikut ini:

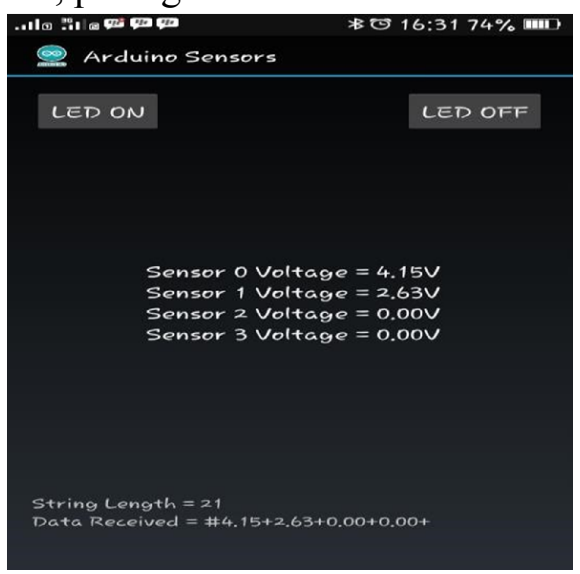

Gambar 6. hasil pengujian pada aplikasi android

\section{SIMPULAN}

Berdasarkan hasil analisa, perancangan dan implementasi yang telah dilakukan, maka kesimpulan yang didapat adalah sebagai berikut: (1) sistem monitoring pencemaran udara ini dapat mengidentifikasi kadar udara berbahaya (seperti kadar karbon monoksida) yang ada di gas buang pada kendaraan bermotor, kemudian memberikan indikasi dan informasi kepada pengguna melalui aplikasi android; (2) Untuk pengembangan sistem, alat uji deteksi kadar gas buang kendaraan bermotor disarankan tidak hanya $\mathrm{CO}, \mathrm{H}_{2}$ dan ETOH saja karena masih banyak gas lainnya yang terdapat pada gas buang kendaraan bermotor yang dapat mengakibatkan pencemaran udara dan berdampak pada kesehatan.

\section{DAFTAR RUJUKAN}

Amqan H, Hasyim Djaffar M. 2006. Buku Bahan Ajar Pencemaran, Udara, Jurusan Kesehatan Lingkungan. Makassar.

Ahsofyan. 2011."Metode Penelitian Model ADDIE".diunduh tanggal 19 Juni 2015.dari https://ahsofyan.wordpress.com/ 2011/12/31/model-evaluasiaddieanalyze-designdevelopmentimplementationdan-evaluation/

Birulinc.2013."Komunikasi serial RS232".diunduh tanggal 6 April 2015. dari http://birulinc.com/prinsipkerjakomunikasiserialrs232/\#sthash. cBMCR3Ri. dpuf

Figaro Engineering.'Dataarchieve Sensor TGS 2201 dan TGS 2600”. 6 
April 2015.dari

http://www.dataarchieve.com

Irawan. 2012. Membuat Aplikasi Android Untuk Orang Awam. Palembang: Maxikom

Nuraisyah.2012."Pencemaran

Udara".diunduh pada tanggal 7 April 2015. Dari

http://www.nuraisyah.net/2012/

Sofana. 2008. Membangun Jaringan Komputer. Bandung: Informatika

Wahadoyo Agus. 2012.Buku Android 4: Untuk Pengguna Pemula Tablet \&Handphone. Yogyakarta.

Yulfian Fikri, Sumardi, Budi Setiyono. 2013."Sistem Monitoring Kualitas Udara Berbasis Mikrokontroler Atmega 8535 Dengan Komunikasi Tcp/Ip", Semarang: Universitas Diponegoro 